\title{
Utilisation of research evidence in clinical practice to improve health care delivery- practices, attitudes and challenges faced by physiotherapists in Zimbabwe: a descriptive cross sectional study
}

\author{
Cathrine Tadyanemhandu ${ }^{1 *}$ (D), Precious Chiedza Chiyangwa', Samson Chengetanai ${ }^{2}$, Fidelis Chibhabha ${ }^{3}$
} and Heleen van Aswegen ${ }^{4}$

\begin{abstract}
Background: Decision-making in health care delivery should be based on the best available current, valid and relevant evidence. Healthcare professionals should therefore be well versed with the skills required to make evidence based clinical decisions in patient care. The aims of this study were to investigate the attitudes of physiotherapists towards utilisation of evidence-based practice (EBP) during patient care, identify barriers to the use of EBP and strategies to improve utilisation of EBP.

Method: A descriptive cross sectional study was conducted using a survey questionnaire. Fifty five questionnaires were administered to randomly selected physiotherapists, working in either private or public hospitals in Zimbabwe. The questionnaire collected information on demographics, utilisation of EBP, factors affecting use of EBP and recommendations.

Results: The response rate was $91 \%(n=50)$. Majority of respondents ( $n=30 ; 60.0 \%)$ were female, mean age of respondents was 36.4 years $(S D=9.8)$ and median years of experience was $8.5(I Q R=5-15)$. A positive attitude towards EBP was displayed by 18 of 31 respondents (58.1\%) from private hospitals and 14 of 19 respondents (73.4\%) from public hospitals. All participants indicated that the knowledge obtained through undergraduate training was their major source of evidence-based information whilst a combined 19 respondents (38.0 \%) indicated reading of journals and carrying out research as their main source of evidence. Lack of time was indicated as the major factor influencing utilisation of EBP by respondents. Limited access to online information was reported by 15 of 19 respondents from public hospitals (78.9\%) to be a major factor affecting their EBP. Respondents recommended training for physiotherapists to improve their skills in critical evaluation of research as a way to promote EBP and highlighted the need for organisational support to facilitate access to online sources of EBP in the clinical environment.
\end{abstract}

Conclusion: Physiotherapists in Zimbabwe seem to rely on knowledge obtained from undergraduate training to guide them in patient care with a few highlighting the importance of research activities to guide clinical practice and their involvement in them. There is need to for physiotherapists to make time to acquire information on evidence based treatment methods in order to improve the quality of clinical practice and ultimately the standard of health care delivery.

Keywords: Research utilisation, Evidence based practice, Health care delivery, Physiotherapy, Practices

\footnotetext{
*Correspondence: cathytadya@gmail.com

'Department of Rehabilitation, College of Health Sciences, University Of

Zimbabwe, PO Box AV 178, Avondale, Harare, Zimbabwe

Full list of author information is available at the end of the article
} 


\section{Background}

Evidence based practice (EBP) is defined as the integration of individual clinical expertise with the explicit and judicious use of current best research evidence when making decisions concerning patient care [1] or the integration of best available evidence with clinical expertise and patient values [2]. Health care professionals need to understand EBP and implement it if they are to provide best practice and quality health care [3, 4]. It has been reported that health professionals identify experiencebased knowledge as a source of clinical knowledge with evidence from published research rarely applied during patient care [5]. Physiotherapy as a profession has faced criticisms for not fully utilizing research evidence in clinical practice and for using techniques that lack a strong scientific basis [6]; hence the need to embrace EBP if the profession is to stay relevant.

Research has been done focusing on describing the beliefs, attitudes, knowledge and behaviours of physical therapists towards the implementation of EBP [6-8]. Criticism of the physiotherapy profession includes the fact that interventions used in patient care are often based on expert opinion only or on anecdotal evidence rather than scientific evidence [9]. Turner [6] argues that the influence that education has on physiotherapy practice must be exploited fully to inculcate the necessary skills, raise awareness of evidence sources and ensure a widespread change in attitude to the use of EBP.

Since EBP involves a rigorous process, it is important to consider individual attitudes when aiming to increase the use of EBP among clinicians [10]. Physiotherapists appear to rely more heavily on initial education and training when selecting treatment techniques or modalities instead of using scientific evidence to guide practice thus clinical decision making has been guided by personal experience and expert opinion [11]. Research conducted on the attitudes of physiotherapists towards EBP in some medium and high income countries showed that physiotherapists have a positive attitude when it comes to implementation of EBP $[7,10,12-15]$. Factors reported to improve EBP implementation were possession of a postgraduate qualification, being recently graduated or involvement in on-going research $[13,14]$.

There is a discrepancy between the amount of research information available and its use in clinical practice $([8,16,17]$,$) . New research findings are being$ published daily and practicing physiotherapists need to be in a position to utilise this information when making clinical decisions in order to deliver high quality physiotherapy services to their patients. One of the ways to enhance sustainability of EBP is for research to focus on methods to overcome perceived barriers to its implementation in each setting as barriers or challenges faced maybe different globally.
The aims of this study were to determine the attitudes of practicing physiotherapists towards utilisation of EBP during patient care and to describe the sources of clinical knowledge used by practicing physiotherapists in Zimbabwe. The study also determined barriers associated with implementation of EBP in physiotherapy health care delivery and identified strategies to improve utilisation of EPB among practicing physiotherapists in Zimbabwe.

\section{Methods \\ Study design}

A descriptive cross sectional study using a survey questionnaire was done in January and February 2015. The study was approved by the Medical Rehabilitation Practitioners' Council of Zimbabwe, Joint Research Ethics Committee of College of Health Sciences and Parirenyatwa Group of Hospitals (JREC282/14) and the Medical Research Council of Zimbabwe (MRCZ/B/799).

\section{Participants}

The study population included all registered physiotherapists working in either public or private hospitals in Zimbabwe. The register of the Medical Rehabilitation Practitioners Council of Zimbabwe had 217 registered physiotherapists in the country in January 2015. In Zimbabwe, physiotherapists are only trained at the University of Zimbabwe and the number of graduating students ranges from 12-30 annually. The minimum sample size to show EBP utilisation for the survey was calculated based on the total population $(n=217)$, at $80 \%$ confidence level and a margin error of $5 \%$ was 46 (Epi Info Version 7.1.5.0). A random sample of 55 physiotherapists was selected from the register for inclusion in the survey. Using the list of the registered physiotherapists, every third name on the register was identified and the workplace noted for distribution of the questionnaire.

\section{Procedure}

A self-administered questionnaire that consisted of three sections was used to collect data. The questionnaire was developed through literature search. Data collected in the first section of the survey questionnaire included demographic information such as age, gender, type of institution where employed, years of practice and highest level of qualification obtained. The second section measured physiotherapists'attitudes towards EBP. The expanded EBP Attitude Scale (EBPAS) was adopted [18]. This is a 50 item scale that is used to measure attitudes towards EBP. Some questions on the EBPAS were not included in the survey questionnaire as they did not address the specific research objectives. The final version of the survey questionnaire included 30 items from the EBPAS. The third section of the survey questionnaire 
gathered information on barriers to the use of EBP and sources of knowledge used in clinical practice Additional file 1 . The questionnaire was tested for content validity by two physiotherapy lecturers who peer reviewed it before administration to respondents. No major changes were made to the questionnaire except slight rephrasing that was suggested on some questions. After the corrections were made, a pilot study was conducted at a provincial hospital with four physiotherapists. The aims of the pilot study where to determine how long it would take for respondents to complete the questionnaire. Responses of the pilot study showed that the questionnaire was clear and the respondents took about $45 \mathrm{~min}$ to complete it.

The selected physiotherapists were informed of the aims of the survey, that participation was voluntary and that they were free to withdraw from the survey at any time without penalty. Participants were required to provide written consent to show their willingness to participate. Confidentiality was maintained by coding the questionnaires that were given to participants with a research number.

Questionnaires were handed over to physiotherapists either in their respective hospitals or during the Zimbabwe Physiotherapy Association meeting held on the last Monday of each month. Majority of the physiotherapists in Zimbabwe are based in either Harare or Bulawayo, with few individuals scattered over in the small towns. Physiotherapists were given a week to complete the questionnaires after which a follow up was done.

\section{Data analysis}

Data was analysed using Stata (Version 13). The central tendency was described in terms of mean and variation of data as standard deviations (SD) for normally distributed data and median and interquartile range (IQR) for data not normally distributed. Categorical data like gender, highest level of qualification, EBP utilisation and recommendations were reported as frequencies. $T$ test was used to compare any difference in age between participants from private and public hospitals whilst Mann Whitney $U$ Test was used to compare the rank order of the years of practice between the practitioners from the two types of hospitals. To test for association between categorical data Chi-square test and Fisher's exact were used. A $p$ value of $<0.05$ was taken to be statistically significant.

The EBP practices and utilisation questions were assessed using a five point Likert scale which included the following responses; $5=$ strongly agree, $4=$ agree. $3=$ neutral, $2=$ disagree and $1=$ strongly agree. For the purposes of data analysis, the responses were put into three categories which included; $2=$ agree, $1=$ neutral and $0=$ disagree . The responses given were added and total score obtained was put into a percentage. If the total score was above
$50 \%$ it showed that the participants had high utilisation and positive attitude towards EBP whilst a score below $50 \%$ indicated a low utilisation and negative attitude towards EBP.

\section{Results}

The response rate for the survey was $91 \%$ as 50 of the 55 questionnaires sent out were returned. Of the 50 respondents, $30(60.0 \%)$ were females and the mean age of the respondents was $36.4(\mathrm{SD}=9.8)$ years. Only 7 respondents (14.0\%) had a highest level of qualification of Master of Science degree whilst the rest had Bachelor of Science Honors degrees. Majority of respondents $(n=31 ; 62.0 \%)$ were working in a private institution. The median years of experience for the respondents was $8.5(\mathrm{IQR}=5-15)$ years. There was a significant difference in age $(\mathrm{t}(48)=2.404, p=0.02)$ and also years of practice $(\mathrm{U}=195.0 \mathrm{Z}=1.98, \mathrm{p}=0.04)$ between respondents who worked in a private institution and those who worked in a public institution. On work time allocation, majority of the respondents spent most of their time delivering health services to patients. Under research activities, 12 respondents $(38.7 \%)$ indicated that they spent more than $5 \%$ of their time doing research whilst $19(61.3 \%)$ indicated that they were not involved in any research activities (Table 1).

Respondents were asked if they intended to pursue an advanced degree in the future. Of those who worked in private hospitals, 5 respondents $(16.3 \%)$ indicated they had no intention to pursue an advanced degree, 10 respondents (32.3\%) were not sure and 16 (51.6\%) intended to pursue an advanced degree. Of those who worked in public hospitals, 2 respondents (10.5) had no intention to pursue an advanced degree whilst another 2 $(10.5 \%)$ were not sure but 15 respondents $(79.0 \%)$ had intentions of pursuing a higher degree. Respondents were also asked if they attended continuing professional development workshops at least once a year and all respondents $(100 \%)$ from the private hospitals indicated that they attended whilst 17 respondents $(89.5 \%)$ from the public hospitals indicated they attended.

Twenty-one respondents $(67.7 \%)$ from private hospitals indicated that they were involved in supervision of undergraduate physiotherapy students whilst 14 respondents $(73.7 \%)$ from public hospitals also indicated that it was part of their job responsibilities. Thirteen (41.9\%) and $7(36.8 \%)$ respondents from the private and public hospitals respectively, indicated that they were involved in teaching of undergraduate students.

\section{Evidence based practice utilisation}

Majority of the respondents $(n=47 ; 94.0 \%)$ agreed that they were willing to try new types of therapy or interventions even if they had to follow a treatment manual and 45 respondents $(90.0 \%)$ indicated that they were 
Table 1 Demographic data of the respondents working in a private or public institution $(n=50)$

\begin{tabular}{|c|c|c|c|}
\hline & Private Institution & Public Institution & Test \\
\hline Sample size, $n(\%)$ & $31(62.0)$ & $19(38.0)$ & \\
\hline Gender, $n(\%)$ & & & $X_{2}(1)=0.567 p=0.81$ \\
\hline Females & $19(61.3)$ & $11(57.9)$ & \\
\hline Males & $12(38.7)$ & $8(42.1)$ & \\
\hline Age, mean (SD) & $38.9(11.4)$ & $32.3(4.5)$ & $\mathrm{t}(48)=2.404, p=0.02^{*}$ \\
\hline Highest level of qualification, $n(\%)$ & & & $X_{2}(1)=1.943 p=0.16$ \\
\hline $\mathrm{BSC}$ & $25(80.6)$ & $18(94.7)$ & \\
\hline MSC & $6(19.3)$ & $1(5.3)$ & \\
\hline Years of Practice, median (IQR) & $10(6-20)$ & $7(5-10)$ & $U=195.0(Z=1.98) p=0.04^{*}$ \\
\hline \multicolumn{4}{|l|}{ Work Time allocation } \\
\hline Patient Care (>60 \%) & 25 (80.6) & $17(89.5)$ & $X_{2}(1)=0.683 p=0.40$ \\
\hline Research (>5 \%) & $12(38.7)$ & $4(21.1)$ & $X_{2}(1)=1.168 p=0.19$ \\
\hline Teaching (>5 \%) & $11(35.5)$ & $7(36.8)$ & $X_{2}(1)=0.009 p=0.92$ \\
\hline Other $(>5 \%)$ & $19(61.3)$ & $9(47.4)$ & $X_{2}(1)=0.927 p=0.33$ \\
\hline
\end{tabular}

*denotes statistically significant

willing to use new and different types of therapy or interventions developed by researchers (Table 2). Majority of the respondents $(n=38 ; 76.0 \%)$ disagreed that research based treatments or interventions were not clinically useful or that EBP did not allow one to do clinical reasoning (Table 3).

Looking at the total scores of the statements on EBP utilisation and attitude, 18 respondents $(58.1 \%)$ from the private hospitals and 14 (73.4\%) from the public institution showed a positive attitude towards utilisation of EBP.

\section{Sources of knowledge to guide in decision making}

All respondents from the private and public hospitals indicated their undergraduate training was the major source of knowledge used in current clinical practice. Other sources of knowledge that respondents used to assist in decision making in patient care were attendance of continuing professional development workshops ( $n=45$; $90.0 \%)$, online searches $(n=34 ; 68.0 \%)$, getting ideas from colleagues $(n=27 ; 54.0 \%)$ and reading of journals and participation in research $(n=19 ; 38.0 \%)$.

\section{Factors influencing EBP utilisation and recommendations}

Factors that strongly reduced the utilisation of EBP included lack of time cited by more than $80 \%$ of respondents from private and public hospitals. Other factors were nonavailability of training courses in EBP (80 \%), lack of skills in searching for evidence (70 \%) and limited access to online information (60\%) (Table 4). Respondents from private hospitals $(n=21 ; 67.7 \%)$ recommended evaluating research articles whilst 10 respondents (32.3\%) recommended organisational support. Respondents from public hospitals ( $n$ $=14 ; 73.7 \%$ ) recommended organisational support whilst only 5 respondents $(26.3 \%)$ recommended evaluation of research articles. Organisational support that was stated included accessibility of internet services at the hospital, funding to be provided to attend workshops/conferences, funding for pursuing a higher degree and increase in number of physiotherapists at any hospital.

Table 2 Evidence based practice utilisation and attitude of therapists towards EBP

\begin{tabular}{|c|c|c|c|}
\hline Statement, $n(\%)$ & Disagree & Neutral & Agree \\
\hline 1. I like to use new types of therapy/interventions to help my clients & $1(2.0)$ & $1(2.0)$ & $48(96.0)$ \\
\hline 2. I am willing to try new types of therapy/interventions even if I have to follow a treatment manual & $1(2.0)$ & $2(4.0)$ & $47(94.0)$ \\
\hline 3. I know better than academic researchers how to care for my clients & $21(42.0)$ & $22(44.0)$ & $7(14.0)$ \\
\hline 4. I am willing to use new and different types of therapy/interventions developed by researchers & $1(2.0)$ & $4(8.0)$ & $45(90.0)$ \\
\hline 5. Research based treatments/interventions are not clinically useful & $38.0(76.0)$ & $11(22.0)$ & $1(2.0)$ \\
\hline 6. Clinical experience is more important than using manualized therapy/treatment & $25(50.0)$ & $18(36.0)$ & $7(14.0)$ \\
\hline 7. I would not use manualized therapy/interventions & $37(74.0)$ & $12(24.0)$ & $1(2.0)$ \\
\hline 8. I would try a new therapy/intervention even if it were very different from what I am used to. & 0 & $15(30.0)$ & $35(70.0)$ \\
\hline
\end{tabular}


Table 3 Attitude towards Evidence based practice

\begin{tabular}{|c|c|c|c|}
\hline Statement, $n(\%)$ & Disagree & Neutral & Agree \\
\hline 1. Evidence-based practice detracts from truly connecting with your clients & $47(94.0)$ & $3(6.0)$ & 0 \\
\hline 2. Evidence-based practice makes it harder to develop a strong working alliance & $45(90.0)$ & $5(10.0)$ & 0 \\
\hline 3. Evidence-based practice does not allow you to do clinical reasoning & $38(76.0)$ & $12(24.0)$ & 0 \\
\hline 4. Evidence-based practice is not useful for clients with multiple problems & $32(64.0)$ & $11(22.0)$ & $7(14.0)$ \\
\hline 5. Evidence-based practice is not useful for families with multiple problems & $31(62.0)$ & $13(26.0)$ & $6(12.0)$ \\
\hline 6. Evidence-based practice is not individualized treatment & $31(62.0)$ & $13(26.0)$ & $6(12.0)$ \\
\hline 7. Evidence-based practice is too narrowly focused & $29(58.0)$ & $15(30.0)$ & $6(12.0)$ \\
\hline 8. I am satisfied with my skills as a therapist/case manager & $9(18.0)$ & $4(8.0)$ & $37(74.0)$ \\
\hline 9. A positive outcome in therapy is an art more than a science & $16(32.0)$ & $22(44.0)$ & $12(24.0)$ \\
\hline 10. Therapy is both an art and a science & $1(2.0)$ & $12(24.0)$ & $37(74.0)$ \\
\hline 11. My overall competence as a therapist is more important than a particular approach & $3(6.0)$ & $7(14.0)$ & $40(80.0)$ \\
\hline 12. I don't have time to learn anything new & $45(90.0)$ & $4(8.0)$ & $1(2.0)$ \\
\hline 13. I can't meet my other obligations if I follow the steps needed to deliver evidence based practice & $41(82.0)$ & $8(16.0)$ & $1(2.0)$ \\
\hline 14. I don't know how to fit evidence-based practice into my administrative work & $28(56.0)$ & $19(38.0)$ & $3(6.0)$ \\
\hline 15. Evidence-based practice will cause too much paperwork & $26(52.0)$ & $21(42.0)$ & $3(6.0)$ \\
\hline 16. Learning an evidence-based practice will help me keep my job & $6(12.0)$ & $21(42.0)$ & $23(46.0)$ \\
\hline 17. Learning an evidence-based practice will make it easier to find a place at a different institution & $5(10.0)$ & $20(40.0)$ & $25(50.0)$ \\
\hline 18. I would learn an evidence-based practice if continuing education credits were provided & $7(14.0)$ & $5(10.0)$ & $38(76.0)$ \\
\hline 19. I would learn an evidence-based practice if training were provided & 0 & $3(6.0)$ & $47(94.0)$ \\
\hline 20. I would learn an evidence-based practice if ongoing support was provided & $2(4.0)$ & $1(3.0)$ & $47(94.0)$ \\
\hline 21. I enjoy getting feedback on my job performance & $1(2.0)$ & $1(2.0)$ & $48(96.0)$ \\
\hline 22. Getting feedback helps me to be a better therapist/case manager & 0 & $2(4.0)$ & $48(96.0)$ \\
\hline
\end{tabular}

Table 4 Factors influencing the use of EBP in patient care $(n=50)$

\begin{tabular}{|c|c|c|}
\hline Factors influencing EBP utilisation & Private institution & Public institution \\
\hline \multicolumn{3}{|l|}{ Lack of time } \\
\hline Disagree & $4(12.9)$ & $2(10.5)$ \\
\hline Neutral & $2(6.5)$ & $1(5.3)$ \\
\hline Agree & $25(80.6)$ & $16(84.2)$ \\
\hline \multicolumn{3}{|l|}{ Limited access to online information } \\
\hline Disagree & $6(19.3)$ & $4(21.1)$ \\
\hline Neutral & $10(32.3)$ & \\
\hline Agree & $15(48.4)$ & $15(78.9)$ \\
\hline \multicolumn{3}{|l|}{ Lack of skills in searching for evidence } \\
\hline Disagree & $10(32.3)$ & $3(15.8)$ \\
\hline Neutral & $1(3.2)$ & $1(5.3)$ \\
\hline Agree & $20(64.5)$ & $15(78.9)$ \\
\hline \multicolumn{3}{|c|}{ Unavailability of training courses in EBP } \\
\hline Disagree & $3(9.6)$ & $1(5.3)$ \\
\hline Neutral & $2(6.5)$ & $4(21.0)$ \\
\hline Agree & $26(83.9)$ & $14(73.7)$ \\
\hline
\end{tabular}

\section{Discussion}

\section{Research findings utilisation}

To the authors' knowledge this is the first survey to investigate utilisation of EBP among physiotherapists in Zimbabwe. Pursuing a higher degree and participation in research activities increases the likelihood of utilizing EBP by health professionals $[13,14]$. Our results indicated that there are currently few physiotherapists involved in research activities in Zimbabwe and very few had pursued a degree beyond the Bachelor's level. An obvious gap between the recent research evidence available and the knowledge possessed by practicing physiotherapists exist since the physiotherapists are more involved in patient care and very few participate in research activities. There is need to bridge this gap to ensure that physiotherapists acquire the most recent scientifically proven information in order to improve health care delivery to patients. Our findings were not different from what has been reported in other countries, Turner [6] showed that the physiotherapy profession is somewhat deficient in research readership, research utilisation and the use of scientific method. Strategies must be sought to promote research utilisation in all clinicians as the majority of people involved in research activities are academia who otherwise spend 
very little time delivering health care to patients. As much as it is also acknowledged that experience based knowledge contributes to decision making when delivering care, it is important to use a decision-making paradigm that integrates patient preferences, clinical circumstances, personal experience and scientific evidence into an optimal clinical decision for an individual patient [19-21].

\section{Attitudes towards EBP}

Results from other studies done on EBP show that physiotherapists generally have positive attitudes towards utilisation of EBP $[7,13-15]$. This is in line with the findings of this survey which showed that nearly $64 \%$ of respondents reported a positive attitude towards EBP. If physiotherapists have a positive attitude, it then becomes important to invent ways to promote EBP and make it standard practice by giving the support needed especially organisational support (internet access to online searches, funding workshop attendances, encouraging research output etc.) [10]. Advanced training of physiotherapists should be utilised as a way to promote the use of EBP during patient care, it was good to note that some respondents highlighted they intended to pursue a higher degree. Respondents' involvement in continuing professional developments workshops was encouraging. Our findings were also similar to what was reported in other studies that training was also shown to result in positive attitudes towards EBP [22, 23].

\section{Sources of clinical knowledge}

When asked about their sources of clinical knowledge when it comes to clinical decision making, $100 \%$ of the respondents stated that their undergraduate education played the biggest role to inform their clinical practice. Several studies have reported that many physiotherapists continue to base practice decisions on knowledge obtained during their initial education and/or personal experience, rather than findings from research [10, 11, 17, 24, 25]. Although this is equally important, physiotherapists should not solely rely on this source as interventions change frequently as more research evidence is generated regarding their benefits and risks to patient care. The other sources of knowledge that were highlighted by respondents included continuing professional development workshops, online searches and information obtained from colleagues. This is consistent with findings reported by Stevenson et al. [22] and Dannapfel et al. [26]. Senior and more experienced colleagues usually guide junior physiotherapists by providing information related to patient care. They should therefore be encouraged to upgrade their skills in sourcing best available research evidence so that when they are disseminating information to others, it is of the highest quality. Of interest was that the older physiotherapists in private were less enthusiastic to upgrade their qualifications compared to the younger physiotherapists in public sector. Dannapfel et al. [26] also reported that motivation concerning research use is usually dependent on being generally curious and keen to learn more to develop as a physiotherapist, which is very common in younger physiotherapists.

\section{Barriers to the use of EBP}

As EBP is an involved process, its utilisation is associated with different barriers and challenges that are faced by the health professionals when trying to acquire relevant information as well as deliver EBP. Lack of time was reported to be the major barrier when it comes to EBP utilisation among physiotherapists in Zimbabwe. Although the total number of registered physiotherapists according to the Medical Rehabilitation Practitioner's Council register is 217 , not all of them are practicing. The workload of the respondents is high and might not permit them to research on patients' problems so they end up just making use of the interventions they learnt during undergraduate training or during their years of practice. The influence of the large volumes of patients on EBP utilisation has also been reported in Nigeria Akinbo et al. [14]. Lack of time was reported to be the primary barrier to EBP in other countries [4, 7, 9, 23, 27]. It was also identified as the greatest barrier for nurses and other allied health professionals $[5,10]$. In another study it was reported that lack of time to search and critically appraise literature was hindering the use of EBP [8]. Limited access to online information was also identified as a barrier to EBP $[4,14,15,23,28,29]$. Respondents from public hospitals mainly reported limited access to online information as a barrier compared to the participants from the private hospitals. The reason for this finding is the differences in support structures at the private and public hospitals, as more resources are available in private hospitals to promote online searches using computers or laptops and internet connectivity compared to public hospitals.

Lack of skills in searching for evidence and lack of training has been reported to affect use of EBP [7, 9, 12]. Findings of these surveys showed that a large proportion of practicing physiotherapists lacked the skills to search and evaluate research evidence to inform their clinical practice. This is consistent with results from another study were this was identified as a barrier to EBP [30].

\section{Recommendations/strategies to improve use of EBP}

Organisational support was recommended by respondents from public hospitals in our study. In Sweden, the physiotherapists believed that an organisational culture that supports learning and competence in development activities provides favorable circumstances for research use [26]. For many health professionals, a component of keeping up-to-date involves some form of continuing 
professional education [19, 31]. The organisational support that was recommended included training programmes at affordable prices, funding to pursue a higher degree, more funded continuing professional development workshops, availability of internet access in the departments for online searches, availability of time, invitations to be sent to expert researchers in different areas to come and deliver presentations. Respondents from the private hospitals suggested evaluation of research papers and journal access as ways to improve utilisation of EBP. It has been reported in the literature that private hospitals provide greater support for EBP implementation than public hospitals [32] and this might be the reason why respondents from private hospitals did not mention organisational support as the major recommendation. The recommendations made by respondents in our survey were similar to what was reported in the literature. Support in the form of provision of access to journals [12, 26], journal availability in physiotherapy departments [33], providing continuing education courses [30], allowing more time for reading and discussing research reports $[9,34]$ and provision of incentives Schreiber et al. [35] were some of the strategies that were identified as facilitators to the use of EBP by others.

\section{Limitations}

The study sample was small which limits generalizability of the research findings. During the time the survey was done, not all registered physiotherapists according to the Medical Rehabilitation Professional's Council registry were working in either private or public hospitals. The majority of the physiotherapists who had recently graduated were not working or had left the country to look for job opportunities.

\section{Conclusion and Recommendations}

There is a gap in the acquisition of knowledge from research studies by physiotherapists in Zimbabwe as few respondents reported reading journal articles or participating in research. The majority of the respondents rely on the knowledge obtained from undergraduate training to inform their clinical decision making regarding patient care. Provision of support to physiotherapists in Zimbabwe to eliminate the barriers to EBP identified is important to improve translation of research evidence into clinical practice, as most respondents had a positive attitude towards EBP, and to ensure the highest quality of health care delivery. More workshops and conferences should be organized at affordable prices so that research evidence is disseminated to the practicing clinicians. The respective physiotherapy departments should organize continuing professional development workshops in order to equip the physiotherapists with current evidence. A qualitative study can also be utilised in order to explore the barriers and factors affecting utilisation of EBP during patient care in future studies. In order to improve the quality of care of patients, physiotherapists should not only utilise research evidence of studies done in other countries but they should engage in research activities in the type of patients admitted in the local hospitals. With this approach, the research evidence will be relevant to our setting and also strategies to improve health care will be devised.

\section{Additional file}

Additional file 1: Modified expanded EBP attitude scale. (DOC 88 kb)

\section{Abbreviations}

CPD: Continuing professional development; EBP: Evidence based practice; PT: Physiotherapist

\section{Acknowledgements}

Would like to thank all the physiotherapists who participated in the study and also the Professional Associations that gave permission for the study to be conducted.

\section{Funding}

No funding was received for this study.

Availability of data and materials

All data and materials are available and are with the first author.

\section{Authors' contributions}

$C T$ and $P C$ participated in the design of the study. CT and PC were responsible for the collection of completed questionnaires and data management. CT and PC participated in the performance of statistical analysis. CT, SC and FC contributed to the write up of the manuscript. HvA contributed to the final write up of the manuscript and language editing. All authors read and approved the final manuscript.

\section{Competing interests}

The authors declare that they have no competing interests.

Consent for publication

Not applicable.

Ethics approval and consent to participate

The study was approved by the Joint Research Ethics Committee of College of Health Sciences and Parirenyatwa Group of Hospitals (JREC282/14) and the Medical Research Council of Zimbabwe (MRCZ/B/799). Each questionnaire contained information on the study and the participation was anonymous and voluntary.

\section{Author details}

${ }^{1}$ Department of Rehabilitation, College of Health Sciences, University Of Zimbabwe, PO Box AV 178, Avondale, Harare, Zimbabwe. ${ }^{2}$ Division of Basic Medical Sciences, Faculty of Medicine, National University of Science and Technology, PO Box AC 939, Ascot, Bulawayo, Zimbabwe. ${ }^{3}$ Faculty of Medicine, Midlands State University, P Bag 9055, Gweru, Zimbabwe. ${ }^{4}$ Department of Physiotherapy, School of Therapeutic Sciences, Faculty of Health Sciences. University of the Witwatersrand, Parktown, 2193 Johannesburg, South Africa.

Received: 11 July 2016 Accepted: 12 September 2016 Published online: 29 September 2016 


\section{References}

1. Sackett DL, Rosenberg WM, Gray JA, Haynes R, Richardson W. Evidence based medicine: what it is and what it isn't. Br Med J. 1996;312:71-2.

2. Sackett DL, Straus SE, Richardson WS, et al. Evidence based medicine. How to practice and teach EBM. 2nd ed. Edinburgh: Churchill Livingstone; 2000.

3. Dawes M, Summerskill W, Glasziou P, Cartabellotta A, Martin J, Hopayian K Porzsolt F, Burls A, Osborne J. Sicily statement on evidence-based practice. BMC Med Educ. 2005;5(1):1.

4. Mclnerney P, Suleman F. Exploring knowledge, attitudes, and barriers toward the use of evidence-based practice amongst academic health care practitioners in their teaching in a south African university: a pilot study. Worldviews Evid Based Nurs. 2010;7(2):90-7.

5. Dalheim A, Harthug S, Nelsen RM, Notvedt MW. Factors influencing the development of evidence-based practice among nurses: a self-report survey. BMC Health Serv Res. 2012;12:367.

6. Turner P. Evidence-based practice and physiotherapy in the 1990s. Physiother Theory Pract. 2001:17(2):107-21. Available at: http:// informahealthcare.com/doi/abs/10.1080/095939801750334185.

7. Jette DU, Bacon K, Batty C, Carlson M, Ferland A, Hemingway RD, Hill JC, Ogilvie L, Volk D. Evidence-based practice: beliefs, attitudes, knowledge, and behaviors of physical therapists. Phys Ther. 2003;83:786-805.

8. Salbach NM, Jaglal SB, Nicol K, Rappolt S, Davis D. Practitioner and organisational barriers to evidence-based practice of physical therapists for people with stroke. Phys Ther. 2007;87(10):1-22.

9. Grimmer-Somers K, Lekkas P, Nyland L, Young A, Kumar S. Perspectives on research evidence and clinical practice: a survey of Australian physiotherapists. Physiother Res Int. 2007;12(3):147-61.

10. Heiwe S, Kajermo KS, Lenne' R, Guidette S, Samuelsson M, Andersson, Wengstro YM. Evidence-based practice: attitudes, knowledge and behavior among allied health care professionals. Int J Qual Health Care. 2011;23(2):198-209.

11. Turner P, Whitfield T. Physiotherapists' use of EBP: a cross-national study. Physiother Res Int. 1997;2:17-29.

12. Iles R, Davidson M. Evidence based practice: a survey of physiotherapists' current practice. Physiother Res Int. 2006;11(2):93-103.

13. Nilsagard Y, Lohse G. Evidence-based physiotherapy: a survey of knowledge, behavior, attitudes and prerequisites. Adv Physiother. 2010;12:179-86.

14. Akinbo S, Odebiyi D, Okunola T, Aderoba O. Evidence-based practice: knowledge, attitudes and beliefs of PTs in Nigeria. Internet J Med Inform. 2008:4:2.

15. Graham F, Robertson L, Anderson J. New Zealand occupational therapists' views on evidence-based practice: a replicated survey of attitudes, confidence and behaviours. Aust Occup Ther J. 2013;60(2):120-8.

16. Grol R, Grimshaw J. From best evidence to best practice: effective implementation of change in patients' care. Lancet. 2003;362:1225-30.

17. Suttle CM, Jalbert I, Alnahedh T. Examining the evidence base used by optometrists in the Australia and New Zealand. Clin Exp Optom. 2012;95:18-36.

18. Aarons GA, Cafri G, Lugo L, Sawitzky A. Expanding the domains of attitudes towards evidence-based practice: the EBP attitude scale-50. Adm Policy Ment Health. 2010;39:331-40.

19. O'Brien MA. Keeping up to date: continuing education improvement strategies and evidence based physiotherapy practice. Physiother Theory Pract. 2001;17:187-99.

20. Cornmack JC. Evidence-based practice... what is It and How Do I Do It? J Orthop Sports Phys Ther. 2002;32(10):484-7.

21. Haynes RB, Devereaux P, Guyatt GH. Clinical expertise in the Era of evidence-based medicine and patient choice. ACP J Club. 2002;136:A11-4.

22. Stevenson K, Lewis M, Hay E. Do PTs' attitudes towards evidence-based practice change as a result of an evidence-based educational programme? J Eval Clin Pract. 2004;10(20):207-17.

23. Dizon JM, Grimmer-Somers K, Kumar S. A qualitative study on EBP for Filipino PTs. Open Educ J. 2012;5:1-8.

24. Bridges PH, Bierema $L L$, Valentine $T$. The propensity to adopt evidencebased practice among physical therapists. BMC Health Serv Res. 2007;7:103.

25. Wainwright SF, Shepard KF, Harman LB, Stephens J. Factors that influence the clinical decision making of novice and experienced physical therapists. Phys Ther. 2011;91:87-101.

26. Dannapfel P, Peolsson A, Nilsen P. What supports physiotherapists' use of research in clinical practice? A qualitative study in Sweden. Implement Sci. 2013;8:31

27. Brown CE, Wickline MA, Ecoff L, Glaser D. Nursing practice, knowledge, attitudes and perceived barriers to evidence-based practice at an academic medical center. J Adv Nurs. 2009;65(2):371-81.
28. Karin H, Filip S, Jo G, Bert A. Obstacles to the implementation of evidencebased physiotherapy in practice: a focus group-based study in Belgium (Flanders). Physiother Theory Pract. 2009;25(7):476-88.

29. Stronge M, Cahill M. Self-reported knowledge, attitudes and behaviour towards evidence-based practice of occupational therapy students in Ireland. Occup Ther Int. 2012;19(1):7-16.

30. Schreiber J, Stern P. A review of literature on EBP in physical therapy. Internet J Allied Health Sci Pract. 2005;3(4):42.

31. Keller PR. The evidence in evidence-based practice. Why the confusion? Clin Exp Optom. 2012;95(6):618-20.

32. Aarons GA, Sommerfeld DH, Walrath-Greene CM. Evidence-based practice implementation: the impact of public versus private sector organisation type on organisational support, provider attitudes, and adoption of evidence-based practice. Implement Sci. 2009;4:83.

33. Turner $P$, Mjolne I. Journal provision and the prevalence of journal clubs: a survey of physiotherapy departments in England and Australia. Physiother Res Int. 2001;6(3):157-69.

34. Kamwendo K. What do Swedish physiotherapists feel about research? A survey of perceptions, attitudes, intentions and engagement. Physiother Res Int. 2002;7(1):23-34

35. Schreiber J, Stern P, Marchetti G, Provident I. Strategies to promote evidence-based practice in pediatric physical therapy: a formative evaluation pilot project. Phys Ther. 2009;89(9):918-33.

\section{Submit your next manuscript to BioMed Central and we will help you at every step:}

- We accept pre-submission inquiries

- Our selector tool helps you to find the most relevant journal

- We provide round the clock customer support

- Convenient online submission

- Thorough peer review

- Inclusion in PubMed and all major indexing services

- Maximum visibility for your research

Submit your manuscript at www.biomedcentral.com/submit
Biomed Central 